\title{
Decreasing the commutation failure frequency in HVDC transmission systems
}

\author{
Hansen (retired June, 2000), Arne; Havemann (retired June, 2000), Henrik
}

Published in:

IEEE Transactions on Power Delivery

Link to article, DOI:

$10.1109 / 61.871369$

Publication date:

2000

Document Version

Publisher's PDF, also known as Version of record

Link back to DTU Orbit

Citation (APA):

Hansen (retired June, 2000), A., \& Havemann (retired June, 2000), H. (2000). Decreasing the commutation failure frequency in HVDC transmission systems. IEEE Transactions on Power Delivery, 15(3), 1022-1026. https://doi.org/10.1109/61.871369

\section{General rights}

Copyright and moral rights for the publications made accessible in the public portal are retained by the authors and/or other copyright owners and it is a condition of accessing publications that users recognise and abide by the legal requirements associated with these rights.

- Users may download and print one copy of any publication from the public portal for the purpose of private study or research.

- You may not further distribute the material or use it for any profit-making activity or commercial gain

- You may freely distribute the URL identifying the publication in the public portal

If you believe that this document breaches copyright please contact us providing details, and we will remove access to the work immediately and investigate your claim. 


\title{
Decreasing the Commutation Failure Frequency in HVDC Transmission Systems
}

\author{
Arne Hansen and Henrik Havemann
}

\begin{abstract}
In this paper we show how a fairly large proportion of those commutation failures that are due to single-phased short circuits to earth can be avoided. In a control circuit based on a digital signal processor (DSP) it is possible, with instantaneous results, to switch from a normal control strategy with equidistant firing pulses to a strategy that takes into consideration the potentially dangerous voltage changes on the supply lines.

If the supply voltages are monitored continuously, it is possible to calculate the necessity of advancing the firing pulses to avoid commutation failures.

In the paper such a calculation technique is described. The monitoring times may be approximately $50 \mu \mathrm{sec}$ apart corresponding to a distance of 0.016 radians or about $1^{\circ}$.
\end{abstract}

Index Terms-Commutation failures, digital control, HVDC transmission.

\section{INTRODUCTION}

$\mathbf{M}$ ANY AUTHORS have considered the possibilities of reducing the risk of commutation failures. The crucial question has been formulated by Thio [1] as follows: "Are there ways of decreasing the commutation failure frequency other than by simply increasing the commutation margin angle which has other negative side effects?"

The answer is yes! In this paper we show that it is possible to avoid a number of those commutation failures that are due to faults resulting from single-phased short circuits to earth on the supply line. The idea is to continuously monitor the supply line voltage and to calculate whether a particular voltage change is so dangerous that it becomes necessary to advance the firing time for the thyristors. If this is the case the control strategy is changed immediately, which is possible in control circuits based on a digital signal processor (DSP). If an advance of the firing pulses unnecessary, the normal control strategy, which assures a predetermined commutation margin, is upheld.

We have designed and tested a DSP based control circuit and have used it in a scale model of a HVDC system. The main purpose was initially to evaluate how often it is possible to perform the necessary monitoring and associated computations.

We have used a DSP that requires $30 \mathrm{nsec}$ for every instruction, and an A/D converter with a conversion time of $35 \mu \mathrm{sec}$. With this equipment the monitoring times can be spaced at $50 \mu \mathrm{sec}$ intervals corresponding to a distance of 0.016 radians or about $1^{\circ}$. In the long term we will enhance the scale model with a model of the ac transmission network, which will allow an experimental evaluation of the new control strategy.

Manuscript received November 23, 1998; revised November 18, 1999.

The authors are with the Department of Electric Power Engineering, Technical University of Denmark, Building 325, DK-2800, Lyngby, Denmark.

Publisher Item Identifier S 0885-8977(00)07217-4.

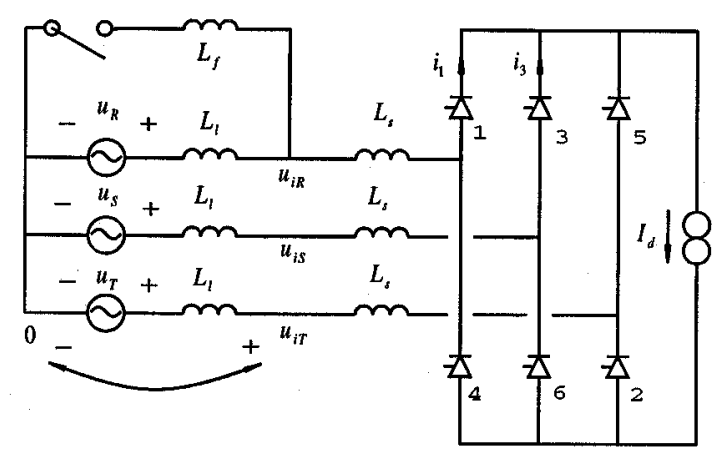

Fig. 1. Equivalent circuit for single-phase short circuit to earth.

The most common failure type in an ac transmission network is a single phase short circuit to earth, and we have therefore for the time being investigated only this type of fault.

For clarification the idea is illustrated with an example that uses a six pulse coupling with a YY transformer. It is furthermore assumed that the dc current does not change significantly, when the single phase short circuit to earth occurs. We have chosen to use this approximation, because in a follow-up paper we will demonstrate that the unavoidable current overshoot can be treated as a fairly simple correction to the observations discussed in this paper.

\section{Commutation Failure Caused by Single-Phase Fault}

Fig. 1 shows the equivalent circuit diagram for a converter that uses a six pulse coupling with a YY transformer.

When the switch shown is closed, a single-phase short circuit to earth occurs. The transformer is not shown, and all values are referred to the primary side of the transformer. The inductance $L_{s}$, represents the stray inductance in the transformer. Additionally, Fig. 1 includes the inductance $L_{l}$ which represents the line inductance from the power generating plant to the converter. The inductance $L_{f}$ is the inductance between the primary side of the converter transformer to the point of failure. If the fault occurs close to the converter, $L_{f}$ is small, and this results in a large change in the voltage $u_{i R}$ on the input side of the transformer.

In Fig. 2 is shown the condition where a single-phase short circuit to earth results in a commutation failure. At time $t_{1}$ a single-phase short circuit to earth occurs on phase $R$, and the voltage $u_{i R}$ is reduced. The firing time $\alpha / \omega$ is not changed with respect to normal operation, and the reduced voltage means that the commutation between thyrisor 1 and thyristor 3 fails. 


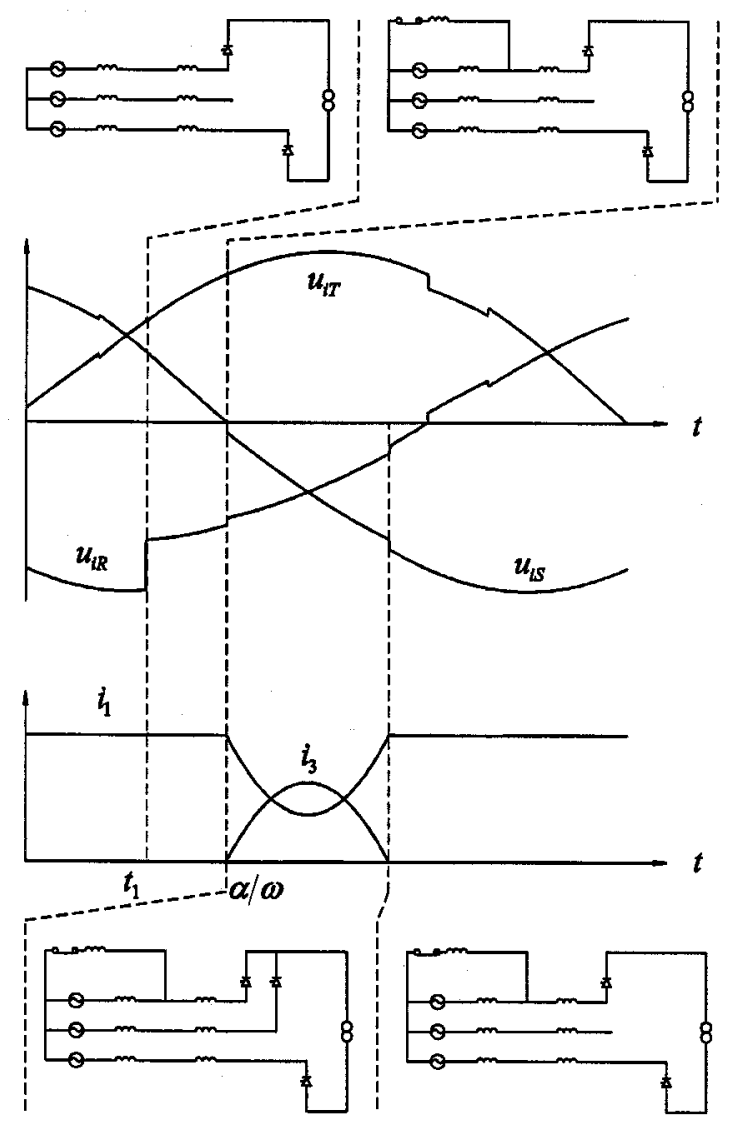

Fig. 2. Commutation failure.

With a DSP based control circuit it is possible as mentioned earlier to advance the firing time very quickly, if a calculation shows that a dangerous voltage change is present.

However, there is no reason to advance the firing time more than necessary, and this means that the monitoring and computations can continue after the time $t_{1}$. At some time $t_{2}$ after $t_{1}$ the computations will show that the voltage changes are potentially dangerous, and the firing time must be moved forward to $t_{2}$.

In Fig. 3 the firing time has been advanced to a point where a commutation failure is just avoided.

Just before the time $t$, on Figs. 2 and 3 the following holds

$$
u_{i R}\left(t_{1}-\right)=u_{R}
$$

Just after the single-phase short circuit to earth has occurred, but before the start of commutation, the following is valid

$$
u_{i R}\left(t_{1}+\right)=u_{R} \cdot \frac{L_{f}}{L_{l}+L_{f}} .
$$

The voltage change is thus

$$
\Delta u=u_{i R}\left(t_{1}-\right)-u_{i R}\left(t_{1}+\right)=u_{R} \cdot\left(1-\frac{L_{f}}{L_{1}+L_{f}}\right) .
$$

This value can be registered by monitoring the voltages directly on the input of the converter.

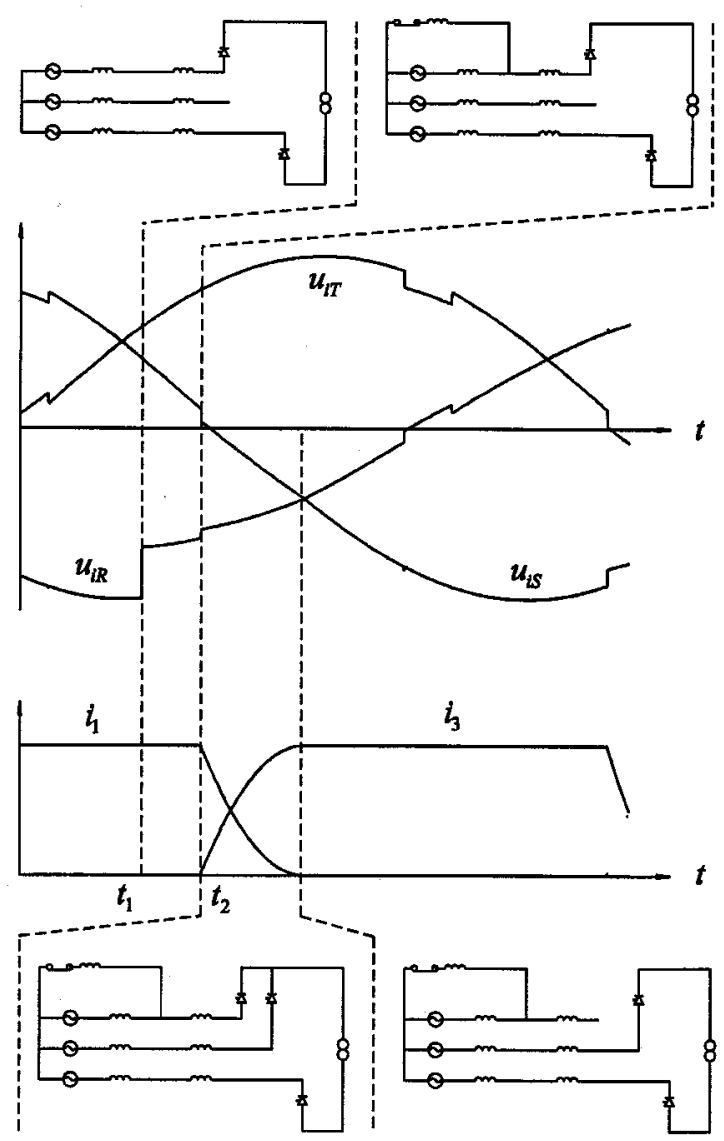

Fig. 3. Successful commutation.

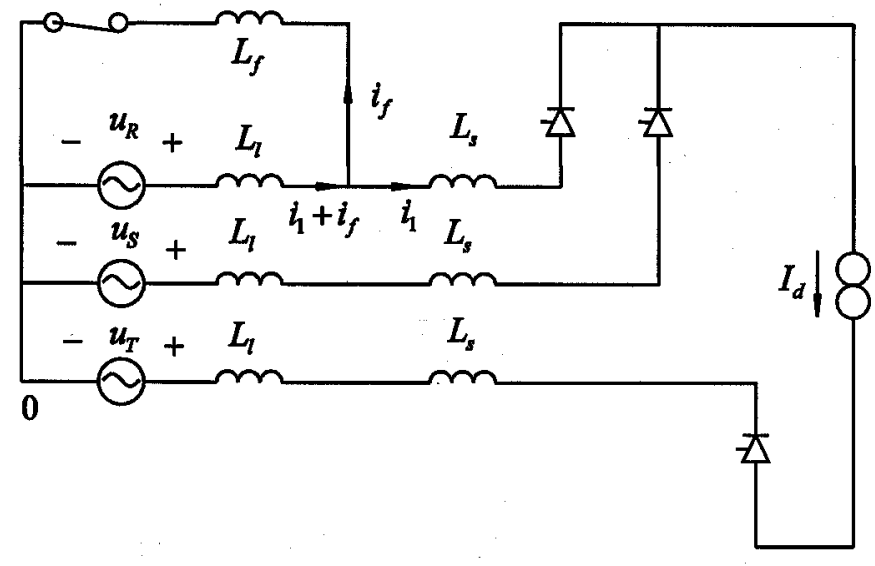

Fig. 4. Equivalent circuit for supply network and converter.

\section{THEORETICAL DEVELOPMENT}

When a single-phase short circuit to earth occurs at the time when the commutation starts, the equivalent diagram of Fig. 4 applies.

The phase voltages may be written as

$$
u_{R}=\sqrt{2} \cdot E \cdot \cos \left(\omega \cdot t+\frac{\pi}{3}\right)
$$




$$
\begin{aligned}
& u_{S}=\sqrt{2} \cdot E \cdot \cos \left(\omega \cdot t-\frac{\pi}{3}\right) \\
& u_{T}=\sqrt{2} \cdot E \cdot \cos (\omega \cdot t-\pi) .
\end{aligned}
$$

For the circuit of Fig. 4 the following network equations can be written

$$
\begin{aligned}
u_{R}-u_{S} & =L_{l} \cdot\left(\frac{d i_{1}}{d t}+\frac{d i_{f}}{d t}\right)+\left(2 \cdot L_{s}+L_{l}\right) \cdot \frac{d i_{1}}{d t} \\
u_{R} & =L_{l} \cdot\left(\frac{d i_{1}}{d t}+\frac{d i_{f}}{d t}\right)+L_{f} \cdot \frac{d i_{f}}{d t} .
\end{aligned}
$$

The value of $d i_{f} / d t$ is determined by (5) and inserted in (6)

$$
\begin{aligned}
u_{R}-u_{S}= & L_{l} \cdot \frac{d i_{1}}{d t}+\frac{L_{l}}{L_{l}+L_{f}} \cdot\left(u_{R}-L_{l} \cdot \frac{d i_{1}}{d t}\right) \\
& +\left(2 \cdot L_{s}+L_{1}\right) \cdot \frac{d i_{1}}{d t}
\end{aligned}
$$

If the time dependent expressions for $u_{R}$ and $u_{S}$ from (4) are inserted, you find what is shown in (8) at the bottom of the page.

If (3) is introduced in this expression, you have what is shown in (9) at the bottom of the page. The minimum value of $i_{1}$ occurs at an angle $\zeta$ which is less than $\pi$. The parameter $\zeta$ can be found by setting the numerator of (9) to zero

$$
0=\left(1-\frac{\Delta u}{u_{R}}\right) \cdot \cos \left(\zeta+\frac{\pi}{3}\right)-\cos \left(\zeta-\frac{\pi}{3}\right)
$$

It may be shown that the solution to this equation is

$$
\zeta=\pi-\arctan \left(\frac{\frac{\Delta u}{u_{R}}}{\sqrt{3} \cdot\left(2-\frac{\Delta u}{u_{R}}\right)}\right)
$$

The current $i_{1}$ may be determined by integrating (9), and if $\omega t=$ $\zeta$ is introduced you find the minimum value of $i_{1}$.
The minimum value must be negative if the commutation is to succeed. At the boundary, where the minimum value is precisely equal to zero, the following formula holds

$$
\begin{aligned}
0= & \frac{\sqrt{2} \cdot E}{\omega \cdot\left(L_{l} \cdot\left(1-\frac{\Delta u}{u_{R}}\right)+2 \cdot L_{s}+L_{l}\right)} \\
& \cdot\left[\left(1-\frac{\Delta u}{u_{R}}\right) \cdot \sin \left(\zeta+\frac{\pi}{3}\right)-\sin \left(\zeta-\frac{\pi}{3}\right)\right. \\
& \left.-\left(\left(1-\frac{\Delta u}{u_{R}}\right) \cdot \sin \left(\alpha+\frac{\pi}{3}\right)-\sin \left(\alpha-\frac{\pi}{3}\right)\right)\right]+I_{d} .
\end{aligned}
$$

From (11) it may be seen that $\zeta$ is a function of $\Delta u / u_{R}$. This means that you must use numerical methods to find $\Delta u / u_{R}$ as a function of $\alpha$ using (11) and (12). The allowable change of voltage on the input of the converter transformer may then be found as

$$
\Delta u=\frac{\Delta u}{u_{R}} \cdot u_{R}
$$

The formulas are used in the following numerical example:

- $E=213 \mathrm{kV}$.

- $L_{s}=146 \mathrm{mH}$.

- $L_{l}=33.9 \mathrm{mH}$.

- $I_{d}=615 \mathrm{~A}$.

The results are as shown in Fig. 5.

From Fig. 5 it may be seen that if you intervene at an early stage, you can avoid commutation failure even if fairly large voltage changes occur.

\section{DSP-BASED CONTROLLER}

\section{A. Normal Operation}

That part of the DSP based control circuit that performs the control under normal operating circumstances is designed as a combination of the ideas discussed by Dewan [2] and Sood [3].

$$
\frac{d i_{1}}{d t}=\frac{\frac{L_{f}}{L_{l}+L_{f}} \cdot \sqrt{2} \cdot E \cdot \cos \left(\omega \cdot t+\frac{\pi}{3}\right)-\sqrt{2} \cdot E \cdot \cos \left(\omega \cdot t-\frac{\pi}{3}\right)}{\frac{L_{l} \cdot L_{f}}{L_{l}+L_{f}}+2 \cdot L_{s}+L_{l}}
$$

$$
\frac{d i_{1}}{d t}=\frac{\left(1-\frac{\Delta u}{u_{R}}\right) \cdot \sqrt{2} \cdot E \cdot \cos \left(\omega \cdot t+\frac{\pi}{3}\right)-\sqrt{2} \cdot E \cdot \cos \left(\omega \cdot t-\frac{\pi}{3}\right)}{L_{l} \cdot\left(1-\frac{\Delta u}{u_{R}}\right)+2 \cdot L_{s}+L_{l}}
$$




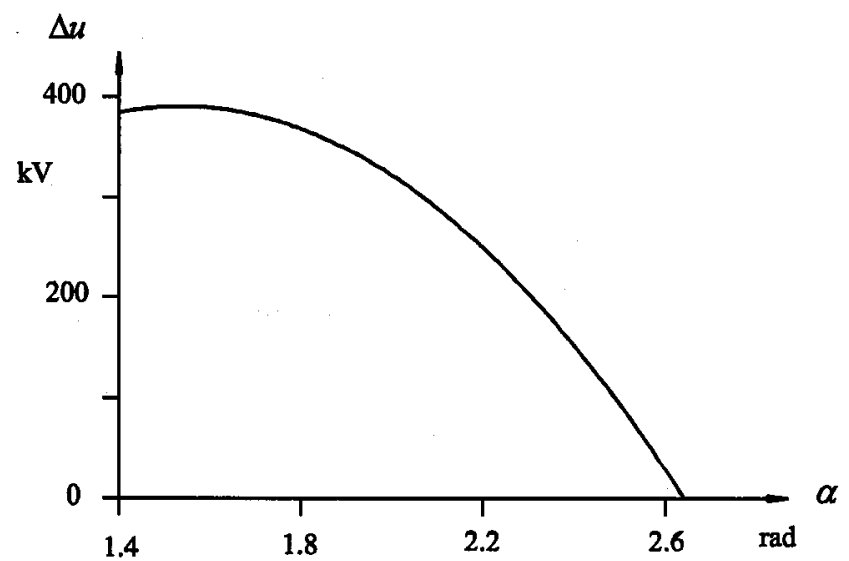

Fig. 5. Allowable voltage change for the numerical example.

The line-to-line voltages are measured and transformed to the voltages $u_{\alpha}$ and $u_{\beta}$ using the expressions (14)

$u_{\alpha}=\hat{u} \cdot \sin (\theta)=\frac{2 \cdot\left(u_{S s}-u_{R}\right)-\left(u_{T}-u_{S}\right)-\left(u_{R}-u_{T}\right)}{3}$
$u_{\beta}=-\hat{u} \cdot \cos (\theta)=\frac{\left(u_{T}-u_{S}\right)-\left(u_{R}-u_{T}\right)}{\sqrt{3}}$.

The determination of the angle $\theta$ over a period of the supply voltage can be made using $u_{\alpha}$ and $u_{\beta}$. This may for example be done by using a table stored in the memory of the signal processor.

In Fig. 6 , the angle $\theta$ as a function of $\omega t$. To generate the firing pulses to the thyristors a counter is used. This is on Fig. 6 represented by a saw tooth with a frequency six times that of the supply frequency. Every time the counter has counted down to zero, a thyristor is turned on. The counter must therefore be synchronized to the supply voltage in such a way that it reaches zero at the control angle $\alpha$ as shown in Fig. 6. Also shown are the gate signals for thyristors 1,2 , and 3 .

The angle $\theta$ is sampled every sixth counting period, and the sampled value is compared to the desired value of the control angle $\alpha$. A regulating system adjusts the counter's maximum number in accordance with the result of the comparison.

The sampling of the line-to-line voltages is performed immediately after a thyristor is turned on. In the present version of the control circuit an A/D converter with a conversion time of about $35 \mu \mathrm{sec}$ is used. The computation time of the regulating circuit is negligible in comparison.

For every counting period a sampling of the dc current in the converter is performed, and another regulating system assures that this current is held to the desired value.

Fig. 7 shows at the top a single counting period. The sampling, the conversions, and the calculations required for normal operation are concluded after the first approximately $50 \mu \mathrm{sec}$ of a counting period. The time remaining may be used to monitor the line-to-line voltages in order to possibly advance the commutation time.
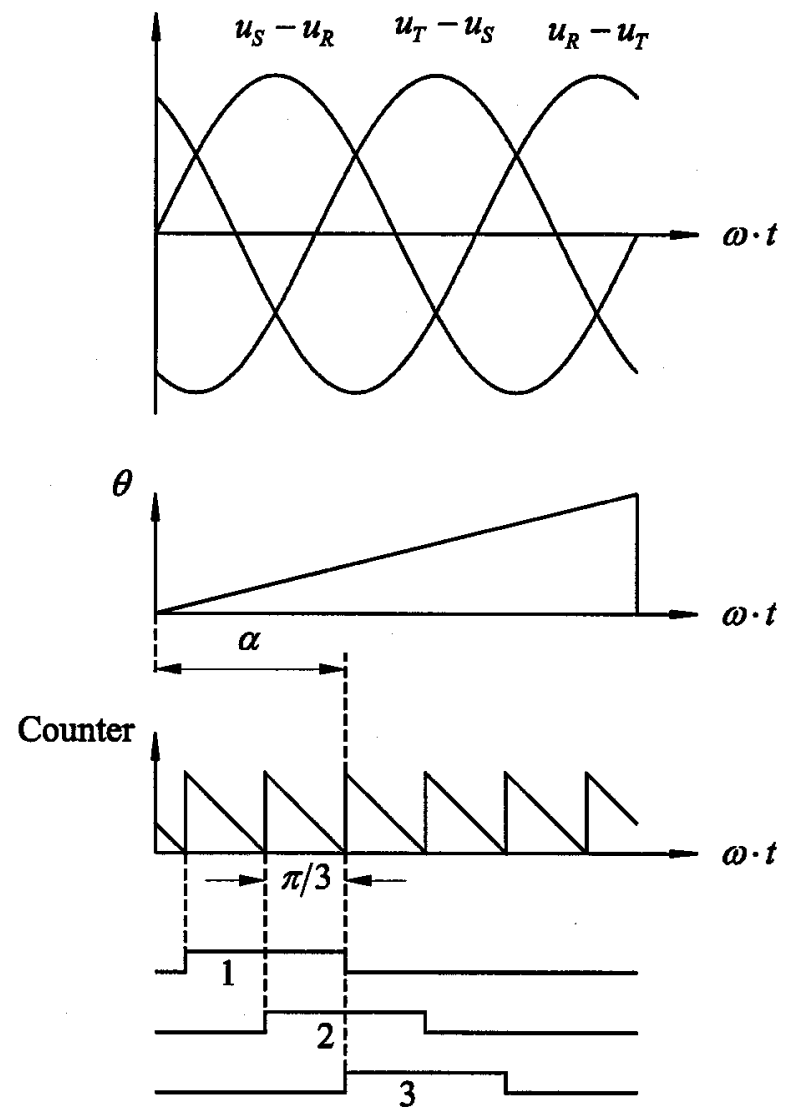

Fig. 6. The principle of the control circuit.

\section{B. Monitoring and Advancing the Firing Time}

In Fig. 7 time zero has been chosen as the time where thyristor 2 is turned on. In determining the timing, a commutation margin of $\gamma=0.175$ radians, corresponding to $10^{\circ}$ has been chosen.

Fig. 7 shows the value of the voltage change $\Delta u$ in the chosen time interval. Because of the chosen value of $\gamma, \Delta u=21.6 \mathrm{kV}$ at the normal point of commutation $(t=3.33 \mathrm{msec})$.

If a single-phased short circuit to earth gives a voltage change in excess of $21.6 \mathrm{kV}$ a commutation failure will occur, unless the firing time for thyristor 3 is advanced. The relevant commutation must be performed from thyristor 1 to thyristor 3 , and it is the line-to-line voltage $u_{S}-u_{R}$ that must be monitored in the counting interval shown.

The monitoring interval is more than $3 \mathrm{msec}$ long, as it starts about $50 \mu \mathrm{sec}$ into the interval and finishes about $50 l \mu \mathrm{sec}$ before the next normal commutation.

In the monitoring interval the voltage $u_{S}-u_{R}$ is sampled as often as possible, and the conversion time for the A/D converter can be used to compute the allowable voltage change $\Delta u$. When the conversion is concluded, you will know if it is necessary to advance the firing time and change the control strategy.

In Fig. 7 it is assumed that a single-phased short circuit to earth occurs at $t=1.5 \mathrm{msec}$, and the change $u_{S}-u_{R}$ becomes 


\section{Thyristor 2 turnes on and line-to-line voltages are sampled}

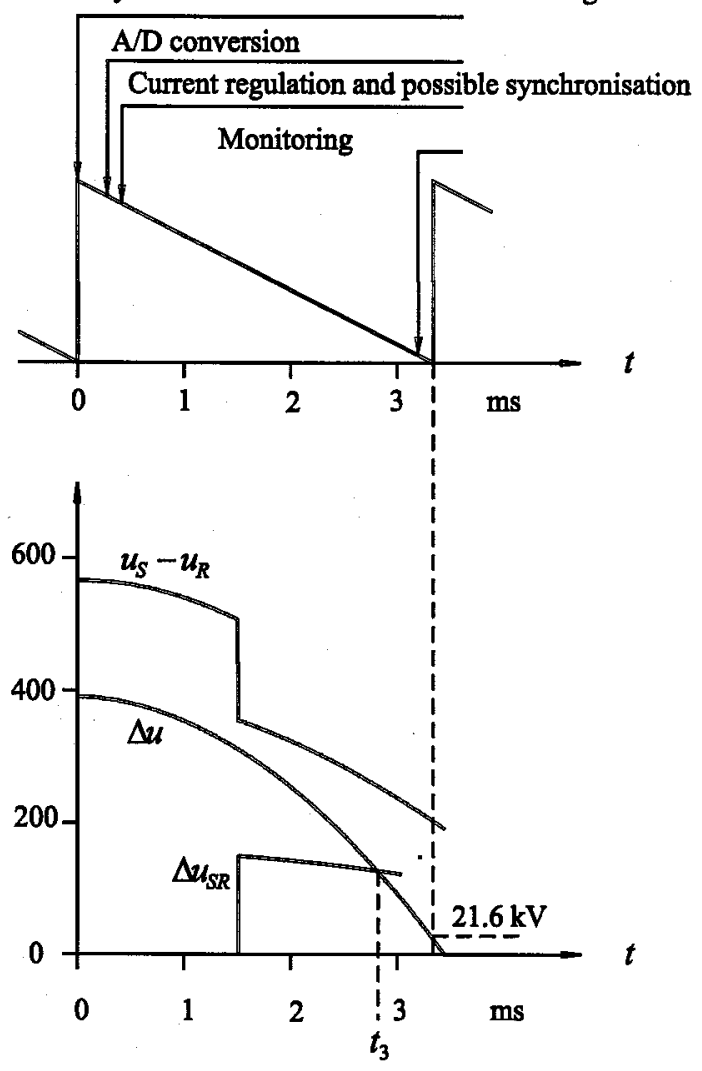

Fig. 7. Monitoring and advancing the firing time.

approximately $150 \mathrm{kV}$ at this time. $\Delta u_{S R}$ is the change from the standard progression and as $\Delta u>\Delta u_{S R}$ for $t=1.5 \mathrm{msec}$ there is no need advance the firing time for thyristor 3 .

The sampling of $u_{S}-u_{R}$ and the accompanying computations can continue until shortly before $t_{3}$. Only at that point will it be necessary to advance the firing time for thyristor 3 in order to avoid a commutation failure.
From Fig. 7 it may be seen that it is possible to avoid commutation failures in a large part of the monitoring interval, even when the voltage changes are quite substantial, and the method described means that a possible advance of the firing time becomes as small as possible.

\section{CONCLUSION}

In this paper we have presented a method for the reduction of the risk of having a commutation failure in a HVDC system. The method requires a continuous monitoring of the network voltages and a computation of the point of time where an observed voltage change will necessitate a change in control strategy.

When a change is required, a pre-computed advancement of the firing time for all thyristors is used. A numerical example shows that you in many instances can avoid a commutation failure even with a fairly large change in voltage.

\section{REFERENCES}

[1] C. V. Thio, J. B. Davies, and K. L. Kent, "Commutation failures in HVDC transmission systems," IEEE Trans. Power Delivery, vol. 11, no. 2, pp. 946-957, Apr. 1996.

[2] S. B. Dewan and W. G. Dunford, "A microprocessor-based controller for a three-phase controlled rectifier bridge," IEEE Trans. Industry Applications, vol. IA-19, no. 1, pp. 113-119, Jan./Feb. 1983.

[3] V. K. Sood, V. Khatri, and H. Jin, "Performance assessment using EMTP of two gate firing units for HVDC converters operating with weak AC systems," in IPST'95 International Conference on Power Systems Transients, Lisbon, Sept. 3-7, 1995, pp. 517-522.

Arne Hansen was born in Copenhagen, Denmark, on May 9, 1937. He graduated with a master degree in electrical engineering in 1962. Since 1963, he has been employed at the Technical University. From 1996, he worked at the Department of Electrical Power Engineering and he is now working HVDC.

Henrik Havemann was born in Copenhagen, Denmark, on October 10, 1937. He graduated with a master degree in electrical engineering in 1962. Since 1965, he has been employed at the Technical University. From 1996, he worked at the Department of Electrical Power Engineering and he is now working HVDC. 